\title{
Achievement of LDL-C Targets Defined by ESC/EAS (2011) Guidelines in Risk-Stratified Korean Patients with Dyslipidemia Receiving Lipid-Modifying Treatments
}

\author{
Ye Seul Yang ${ }^{1}$, Seo Young Lee ${ }^{1}$, Jung-Sun $\mathrm{Kim}^{2}$, Kyung Mook Choi ${ }^{3}$, Kang Wook Lee ${ }^{4}$, Sang-Chol Lee ${ }^{5}$, \\ Jung Rae $\mathrm{Cho}^{6}$, Seung-Jin $\mathrm{Oh}^{7}$, Ji-Hyun $\mathrm{Kim}^{8}$, Sung Hee Choi ${ }^{1,9}$ \\ ${ }^{1}$ Department of Internal Medicine, Seoul National University College of Medicine; ${ }^{2}$ Division of Cardiology, Severance \\ Cardiovascular Hospital, Yonsei University College of Medicine; ${ }^{3}$ Division of Endocrinology and Metabolism, Department of \\ Internal Medicine, Korea University Guro Hospital, Seoul; ${ }^{4}$ Division of Nephrology, Department of Internal Medicine, \\ Chungnam National University Hospital, Chungnam National University College of Medicine, Daejeon; ${ }^{5}$ Division of \\ Cardiology, Department of Medicine, Samsung Medical Center, Sungkyunkwan University School of Medicine; \\ ${ }^{6}$ Cardiovascular Division, Department of Internal Medicine, Hallym University Kangnam Sacred Heart Hospital, Seoul; \\ ${ }^{7}$ Division of Cardiology, Department of Internal Medicine, National Health Insurance Service Ilsan Hospital, Goyang; ${ }^{8}$ Medical \\ Affairs, Sanofi-Aventis Korea, Seoul; ${ }^{9}$ Department of Internal Medicine, Seoul National University Bundang Hospital, \\ Seongnam, Korea
}

Background: This study assessed the proportion of risk-stratified Korean patients with dyslipidemia achieving their low-density lipoprotein cholesterol (LDL-C) targets as defined by the European Society of Cardiology/European Atherosclerosis Society (ESC/ EAS) (2011) guidelines while receiving lipid-modifying treatments (LMTs).

Methods: In this multicenter, cross-sectional, observational study, we evaluated data from Korean patients aged $\geq 19$ years who were receiving LMTs for $\geq 3$ months and had an LDL-C value within the previous 12 months on the same LMT. Data were collected for demographics, cardiovascular (CV) risk factors, medical history, and healthcare consumption. Patients were risk-stratified according to the ESC Systematic COronary Risk Evaluation (SCORE) chart and LDL-C target achievement rate was assessed.

Results: Guideline-based risk-stratification of the 1,034 patients showed the majority (72.2\%) to be in the very high-risk category. Investigators' assessment of risk was underestimated in 71.6\% compared to ESC/EAS guidelines. Overall LDL-C target achievement rate was 44.3\%; target achievement was the highest (66.0\%) in moderate-risk patients and the lowest (39.0\%) in very high-risk patients. Overall $97.1 \%$ patients were receiving statin therapy, mostly as a single-agent (89.2\%). High-intensity statins and the highest permissible dose of high-intensity statins had been prescribed to only $9.1 \%$ and $7.3 \%$ patients in the very high-risk group, respectively. Physician satisfaction with patients' LDL-C levels was the primary reason for non-intensification of statin therapy.

Conclusion: Achievement of target LDL-C level is suboptimal in Korean patients with dyslipidemia, especially in those at very high-risk of CV events. Current practices in LMTs need to be improved based on precise CV risk evaluation posed by dyslipidemia.

Keywords: Dyslipidemias; Cholesterol, LDL; Hydroxymethylglutaryl-CoA reductase inhibitors; Practice guideline; Risk assessment; Korea

Received: 16 December 2019, Revised: 19 February 2020,

Accepted: 14 April 2020

Corresponding author: Sung Hee Choi

Department of Internal Medicine, Seoul National University Bundang Hospital, 82 Gumi-ro 173beon-gil, Bundang-gu, Seongnam 13620, Korea

Tel: +82-31-787-7033, Fax: +82-31-787-7042, E-mail: shchoimd@gmail.com
Copyright $\odot 2020$ Korean Endocrine Society

This is an Open Access article distributed under the terms of the Creative Commons Attribution Non-Commercial License (https://creativecommons.org/ licenses/by-nc/4.0/) which permits unrestricted non-commercial use, distribution, and reproduction in any medium, provided the original work is properly cited. 


\section{INTRODUCTION}

Dyslipidemia, characterized by abnormal levels of serum lipids, is a major established risk factor for cardiovascular disease (CVD) [1] and cerebrovascular disease [2] in Korea. At present, these diseases rank as the second- and third-leading cause of mortality in Koreans [3]. According to the results of the Korea National Health and Nutrition Examination Survey (KNHANES), the age-standardized prevalence of dyslipidemia in Korea has risen steadily from $54.0 \%$ in 1998 to $59.0 \%$ in 2010 [4]. For the period 2005 to 2010, awareness and treatment rates for dyslipidemia in Korea were also found to have gradually increased to $13.7 \%$ and $7.4 \%$, respectively [4]. However, these can still be considered as suboptimal.

Various epidemiological studies have shown that low-density lipoprotein (LDL) has negative implications in CVD [5-7]. Korean patients with dyslipidemia have been reported to have a propensity for relatively higher triglycerides (TG) and lower high-density lipoprotein cholesterol (HDL-C) levels. However, in recent years, the incidence of hypercholesterolemia and elevated LDL-cholesterol (LDL-C) levels has been increasing in parallel, without any decrease in hypertriglyceridemia or hypoHDL-cholesterolemia [8]. Further KNHANES database has shown that approximately $10.0 \%$ of Korean adults have LDL-C levels that needed to be pharmacologically lowered, and $19.9 \%$ have LDL-C levels that needed therapeutic lifestyle modifications [9]. Consequently, dyslipidemia stands to substantially increase the cardiovascular (CV) risk in the Korean population and needs to be considered as a major health concern in the Korean setting.

Considering the role of LDL-C as a crucial modifiable CV risk factor, various international guidelines recommend lowering of LDL-C levels to minimize the risk of CV events [10-13]. The recently formulated guidelines from the Committee of Clinical Practice of the Korean Society of Lipid and Atherosclerosis for the Management of Dyslipidemia [14] also recommend the reduction of LDL-C levels to target levels or lower as the first goal for management of dyslipidemia. The discovery of statins has revolutionized dyslipidemia treatment and statins are known to substantially reduce LDL-C levels and reduce CV complications and mortality [15-18]. Besides interfering with the biosynthesis of cholesterol, statins also increase receptormediated uptake of circulating LDL and its precursors [19]. Despite the establishment of guidelines and proven effectiveness of statins for more than a decade, the achievement of LDL-C and total cholesterol (TC) targets in Koreans is suboptimal with current therapeutic options [20,21]. To address this issue, it is vital to assess existing practice patterns for the treatment of dyslipidemia in real clinical settings. A major limitation to such an undertaking is the paucity of data which is applicable to Korea. A recent study in Korean real-world practice has demonstrated good compliance for at least 18 months in patients who had been started with statins at the fixed doses [22]; however, the study was performed at a single institution and lacks generalizability. Moreover, the indices of metabolic syndrome in Korea have historically been TG and HDL-C [9], hence it is not possible to infer LDL-C levels in the general population from the KNHANES database [23].

The International ChoLesterol Management Practice Study (ICLPS) was an observational study [24] designed to ascertain the proportion of patients with moderate to very high $\mathrm{CV}$ risk reaching LDL-C targets as defined by the European Society of Cardiology/European Atherosclerosis Society (ESC/EAS) (2011) guidelines [25] in a real-world setting. In this report, we describe the results from the Korean cohort of the ICLPS. In addition, we also attempt to identify whether the treatment of dyslipidemia in actual practice in Korea differed from that recommended by the guidelines.

\section{METHODS}

\section{Study design}

Data included in the reported sub-analysis was collected from the Korean cohort of ICLPS - an international, multicenter, cross-sectional, observational study conducted at various locations in Eurasia, Asia, Africa, Middle-East, and South America [24].

Study investigators were primarily those physicians who were representatives in the medical community who managed patients with dyslipidemia and included cardiologists, endocrinologists, gerontologists, internists, and general practitioners. Investigators were selected randomly and independently from a pre-established list of physicians that was meant to ensure appropriate proportion of all specialties managing patients with dyslipidemia.

\section{Patient recruitment and data collection}

Patients eligible for inclusion in the study were $\geq 19$ years of age, receiving lipid-modifying treatments (LMTs) for at least 3 months prior to enrollment, and had an LDL-C value measured $<12$ months prior to enrollment while on the same LMT. Use of proprotein convertase subtilisin/kexin type 9 (PCSK9) inhibi- 
tors within 6 months prior to enrollment as well as participation in other trials simultaneously were grounds for study exclusion. The present study was approved by the Institutional Review Board of each study site (IRB number: DSMC 2015-06-009, B1506-304-301, H-1506-102-682, NHIMC 2015-06-008, HYUH 2015-06-010, H-1506-011-030, 2015GR-0156, 15-098, KUGH 2015-06-005, DSMC 2015-06-013, 2015GR-0141, SMC 201507-037-001, UUH 2015-08-007, CHOSUN 2015-06-015, 201512-151, 4-2015-1029, 2015GR-00326, 16-0002, CNUH 2016001-022) and was conducted according to the Declaration of Helsinki. All study patients had to provide informed consent. In order to reduce bias, patients were recruited consecutively at each study site over a limited period of time ( $\leq 2$ weeks). The study involved a single visit during enrollment with no subsequent follow-up.

Data of investigators was collected including age and gender, specialty, years of practice, location, mean number of patients consulted per day (total and with hypercholesterolemia), guidelines adhered to, and definition of statin intolerance used. Data of patients in the Korean cohort was collected between August 2015 and March 2016 and included demographics and socioeconomic profile, physical examination, CV risk factors, dyslipidemia and other medical history, laboratory values, ongoing medications, healthcare consumption (past 12 months), level of CV risk, and target LDL-C value.

Risk stratification of patients was conducted according to the ESC Systematic COronary Risk Evaluation (SCORE) chart [26] and LDL-C target for individual patients was ascertained as defined by ESC/EAS (2011) guidelines (Supplemental Table S1) [25]. Values of both parameters, as defined by the guidelines and as assessed by the investigators, were compared to determine if any gap existed between the guideline and the actual practice. Familial hypercholesterolemia (FH) was assessed/diagnosed using the Dutch Lipid Clinic Network diagnostic criteria [27]. Primary/familial dyslipidemia was defined at least one of the following: (1) FH (heterozygous, homozygous, or unknown), (2) first degree relative with known LDL-C above 95th percentile for age and gender, (3) first degree relative with tendinous xanthomata and/or arcus cornealis. The reason for not prescribing the highest dose of statins was assessed by a questionnaire which was configured to select one of three reasons; physician satisfaction, medically inappropriate, statin intolerance.

\section{Statistical analysis}

The population for analysis consisted of all patients who met the inclusion criteria at enrollment in this study. Furthermore, any investigator who recruited at least one patient was included in analysis of physician profile (Supplemental Table S2). Sample size of the international study [24] was calculated in order to ensure a sufficient precision in the assessment of the qualitative data and the study planned to recruit approximately 11,000 patients from around 700 sites in 35 countries.

Descriptive statistics using counts and percentages for categorical variables and mean, median, standard deviation (SD), and range for continuous variables, were used for data analysis. All statistical analyses were conducted using SAS version 9.2 (SAS Institute, Cary, NC, USA).

\section{RESULTS}

\section{Investigator profile and patient characteristics}

Study investigators $(n=19)$ were mostly male ( $n=16,84.2 \%)$, cardiologists $(n=9,47.4 \%)$, or endocrinologists $(n=6,31.6 \%)$, and had $\geq 15$ years of clinical experience. All investigators reported following guidelines for management of dyslipidemia and the most common were those by the American College of Cardiology/American Heart Association (ACC/AHA) ( $n /$ total number $=13 / 19,68.4 \%)$ and the $\mathrm{ESC} / \mathrm{EAS}(n /$ total number $=6 / 19,31.6 \%$ ). Adherence to domestic [14] and other international guidelines was reported by four $(21.6 \%)$ and three $(15.8 \%)$ investigators, respectively. Some investigators reported following multiple guidelines. About half (52.6\%), 36.8\% and $10.5 \%$ of physicians defined patients as "statin-intolerant" when patients were intolerant to one, two, and more than two statins, respectively.

Investigators enrolled 1,069 patients across Korea in between August 2015 and March 2016 and data from 1,034 was eligible for analysis. Study population comprised $54.9 \%(n=568)$ males and $45.1 \%$ females $(n=466)$ (Table 1$)$. The mean age \pm SD of study population was $63.3 \pm 10.4$ years and $49.7 \%$ of the patients were in the age range $\geq 45$ to $<65$ years.

Commonly prevalent $\mathrm{CV}$ risk factors were hypertension ( $n=730,70.6 \%)$, lack of physical activity $(n=621,60.1 \%)$, and diabetes $(n=517,50.0 \%$ ) (Table 1$)$. Patients in the very highrisk category also had a high prevalence of coronary artery disease $(\mathrm{CAD} ; n /$ total number $=424 / 747 ; 56.8 \%)$. Over half of the very high-risk patients with $\mathrm{CAD}$ presented with acute coronary syndrome (ACS)/myocardial infarction (MI) $(n=254,59.9 \%)$ or percutaneous coronary intervention $(n=246,58.1 \%)$. Elevated consumption of healthcare resources was reported in $22.0 \%$ $(n=227)$ of the overall patients and in $25.3 \%$ ( $n /$ total number $=189 / 747$ ) of the very high-risk patients. 
Table 1. Patient Characteristics, Cardiovascular Risk Factors, and Comorbidities at Enrollment

\begin{tabular}{|c|c|c|c|c|c|c|}
\hline \multirow[b]{2}{*}{ Characteristic } & \multicolumn{5}{|c|}{ Risk category } & \multirow{2}{*}{$\begin{array}{c}\text { Total } \\
(n=1,034)\end{array}$} \\
\hline & $\begin{array}{c}\text { Low } \\
(n=1)\end{array}$ & $\begin{array}{l}\text { Moderate } \\
(n=47)\end{array}$ & $\begin{array}{c}\text { High } \\
(n=178)\end{array}$ & $\begin{array}{l}\text { Very high } \\
(n=747)\end{array}$ & $\begin{array}{c}\text { Non-assessable }{ }^{\mathrm{a}} \\
\quad(n=61)\end{array}$ & \\
\hline Age in years & 30.0 & $56.2 \pm 7.9$ & $60.9 \pm 9.5$ & $64.5 \pm 10.4$ & $62.6 \pm 11.0$ & $63.3 \pm 10.4$ \\
\hline \multicolumn{7}{|l|}{ Gender } \\
\hline Male & 0 & $12(25.5)$ & $76(42.7)$ & $455(60.9)$ & $25(41.0)$ & $568(54.9)$ \\
\hline Female & $1(100)$ & $35(74.5)$ & $102(57.3)$ & $292(39.1)$ & $36(59.0)$ & $466(45.1)$ \\
\hline History of dyslipidemia & $1(100)$ & $47(100)$ & $167(93.8)$ & $536(72.1)$ & $45(73.8)$ & $796(77.0)$ \\
\hline Time in years since diagnosis of dyslipidemia & 1.0 & $4.1 \pm 3.0$ & $5.1 \pm 3.6$ & $5.0 \pm 3.7$ & $4.2 \pm 2.8$ & $4.9 \pm 3.6$ \\
\hline \multicolumn{7}{|l|}{ Prevalence of CV risk factors } \\
\hline Hypertension ${ }^{\mathrm{b}}$ & $1(100)$ & $22(46.8)$ & $100(56.2)$ & $569(76.2)$ & $38(62.3)$ & $730(70.6)$ \\
\hline Lack of physical activity ${ }^{\mathrm{c}}$ & $1(100)$ & $30(63.8)$ & $104(58.4)$ & $446(59.7)$ & $40(65.6)$ & $621(60.1)$ \\
\hline Diabetes $^{\mathrm{d}}$ & 0 & 0 & $140(78.7)$ & $377(50.5)$ & 0 & $517(50.0)$ \\
\hline Regular alcohol consumption ${ }^{\mathrm{e}}$ & 0 & $4(8.5)$ & $32(18.0)$ & $143(19.1)$ & $11(18.0)$ & $190(18.4)$ \\
\hline Familial history of $\mathrm{CVD}^{\mathrm{f}}$ & 0 & $7(14.9)$ & $32(18.0)$ & $137(18.3)$ & $12(19.7)$ & $188(18.2)$ \\
\hline Current smoking ${ }^{g}$ & 0 & $1(2.1)$ & $19(10.7)$ & $116(15.5)$ & $8(13.1)$ & $144(13.9)$ \\
\hline \multicolumn{7}{|l|}{ CV comorbidities } \\
\hline $\mathrm{CAD}$ & 0 & 0 & 0 & $424(56.8)$ & 0 & $424(41.0)$ \\
\hline $\operatorname{ACS} / \mathrm{MI}^{\mathrm{h}}(n=424)$ & NA & NA & NA & $254(59.9)$ & NA & $254(59.9)$ \\
\hline $\mathrm{PCI}^{\mathrm{h}}(n=424)$ & NA & NA & NA & $246(58.0)$ & NA & $246(58.1)$ \\
\hline $\mathrm{CABG}^{\mathrm{h}}(n=424)$ & NA & NA & NA & $16(3.8)$ & NA & $16(3.8)$ \\
\hline Stroke & 0 & 0 & 0 & $140(18.7)$ & 0 & $140(13.5)$ \\
\hline $\mathrm{CKD}^{\mathrm{i}}$ & $1(100.0)$ & $9(19.1)$ & $9(5.1)$ & $94(12.6)$ & $5(8.2)$ & $118(11.4)$ \\
\hline
\end{tabular}

Values are expressed as mean \pm standard deviation or number (\%).

$\mathrm{CV}$, cardiovascular; CVD, cardiovascular disorder; CAD, coronary artery disease; ACS, acute coronary syndrome; MI, myocardial infarction; NA, not applicable; PCI, percutaneous intervention; CABG, coronary artery bypass graft; $\mathrm{CKD}$, chronic kidney disease.

aPatients without a serious pathology classifying them as very high or high cardiovascular risk, and in whom the Systematic COronary Risk Evaluation

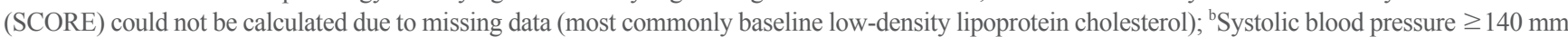
$\mathrm{Hg}$ and/or diastolic blood pressure $\geq 90 \mathrm{~mm} \mathrm{Hg}$ or a previous history of hypertension; 'Patient is not regularly involved in moderate (walking/cycling/ gardening) or strenuous exercise (jogging/football/vigorous swimming) for $\geq 4$ hours each week; ${ }^{\mathrm{d}}$ Type 1 or 2 diabetes mellitus; ${ }^{\mathrm{e}}$ Consumption $\geq 3$ times a week; ${ }^{\mathrm{f} C}$ Coronary and/or vascular disease $<55$ years of age in male and $<60$ years in female first-degree relatives; ${ }^{\mathrm{g}}$ Current smokers and individuals

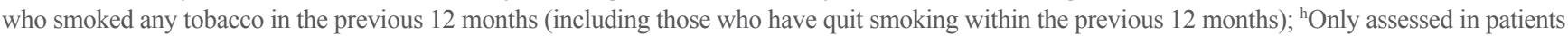
with $\mathrm{CAD} ;{ }^{\mathrm{i}} \mathrm{GFR}<60 \mathrm{~mL} / \mathrm{min} / 1.73 \mathrm{~m}^{2}$.

\section{Risk stratification of study patients according to ESC/EAS (2011) guidelines}

Risk stratification of study patients $(n=1,034)$ according to $\mathrm{ESC} /$ EAS (2011) guidelines classified the patients as-747 (72.2\%) with very high-risk, $178(17.2 \%)$ with high-risk, 47 (4.5\%) with moderate-risk, and one $(0.1 \%)$ with low-risk. A total of 61 (5.9\%) patients were deemed non-assessable for risk according to the guidelines (Fig. 1A). The investigators' assessment of risk was consistent with guideline-based risk assessment in only $20.1 \%(n /$ total number $=150 / 747)$ very high-risk patients, $46.1 \%$ $(n /$ total number $=82 / 178)$ high-risk patients, and $48.8 \%(n /$ total number $=23 / 47$ ) moderate-risk patients (Table 2). Overall, only
$26.2 \%(n /$ total number $=255 / 973)$ of physician's assessment were consistent with the guidelines and in most of the cases ( $n$ / total number $=697 / 973,71.6 \%$ ), and physician underestimated the risk of patients compared to the guideline (Fig. 1B).

\section{Serum LDL-C profile and lipid-modifying treatments prescribed}

A total of 796 (77.3\%) patients had a history of dyslipidemia for a mean \pm SD duration of $4.9 \pm 3.6$ years since diagnosis. Of these patients, $13.3 \%(n=137)$ and $47.0 \%(n=485)$ were reported to have primary (or familial) and secondary hypercholesterolemia, respectively. At first diagnosis, the mean \pm SD values for lipid param- 

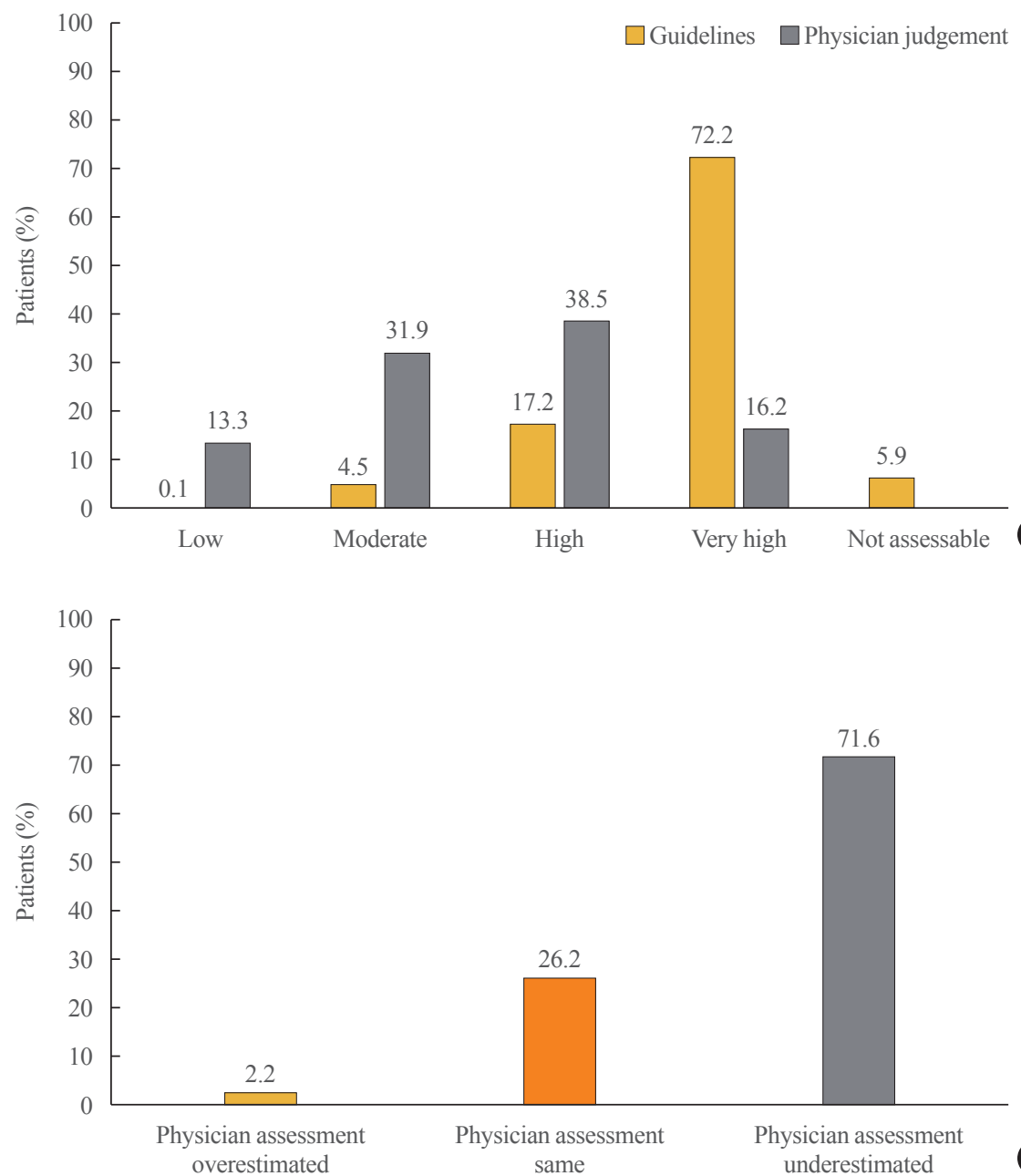

Fig. 1. (A) Comparison of risk stratification according to European Society of Cardiology (ESC) Systematic COronary Risk Evaluation (SCORE) chart [27] and physician judgement. (B) The matching pattern of physician judgement for risk stratification compared to ESC/European Atherosclerosis Society (EAS) 2011 guidelines. Physician assessment overestimated and underestimated were defined as the physician's risk assessment was higher and lower than the risk of the patients according to ESC/EAS guideline, respectively.

Table 2. Risk Assessment According to ESC/EAS 2011 Guidelines versus Risk Assessment by Investigator

\begin{tabular}{|c|c|c|c|c|c|c|}
\hline \multirow[b]{2}{*}{ Risk assessed by investigator } & \multicolumn{5}{|c|}{ Risk category } & \multirow{2}{*}{$\begin{array}{c}\text { Total } \\
(n=1,034)\end{array}$} \\
\hline & $\begin{array}{l}\text { Low } \\
(n=1)\end{array}$ & $\begin{array}{l}\text { Moderate } \\
(n=47)\end{array}$ & $\begin{array}{c}\text { High } \\
(n=178)\end{array}$ & $\begin{array}{l}\text { Very high } \\
(n=747)\end{array}$ & $\begin{array}{l}\text { Non-assessable }{ }^{\mathrm{a}} \\
\quad(n=61)\end{array}$ & \\
\hline Low & $0^{\mathrm{a}}$ & $20(42.6)$ & $39(21.9)$ & $65(8.7)$ & $14(23.0)$ & $138(13.3)$ \\
\hline Moderate & $1(100)$ & $23(48.9)^{\mathrm{a}}$ & $41(23.0)$ & $226(30.3)$ & 39 (63.9) & 330 (31.9) \\
\hline High & 0 & $4(8.5)$ & $82(46.1)^{\mathrm{a}}$ & $306(41.0)$ & $6(9.8)$ & $398(38.5)$ \\
\hline Very high & 0 & 0 & $16(9.0)$ & $150(20.1)^{\mathrm{a}}$ & $2(3.3)$ & $168(16.2)$ \\
\hline
\end{tabular}

eters were: LDL-C, $138.2 \pm 40.3 \mathrm{mg} / \mathrm{dL} ; \mathrm{TC}, 215.9 \pm 45.9 \mathrm{mg} / \mathrm{dL}$; HDL-C, $48.0 \pm 12.9 \mathrm{mg} / \mathrm{dL}$; and TG, $179.3 \pm 123.7 \mathrm{mg} / \mathrm{dL}$. In

Copyright $(C) 2020$ Korean Endocrine Society comparison, mean values for lipid parameters at enrollment were: LDL-C, $83.6 \pm 26.3 \mathrm{mg} / \mathrm{dL} ; \mathrm{TC}, 154.3 \pm 35.3 \mathrm{mg} / \mathrm{dL} ;$ HDL-C, 


\section{$50.1 \pm 13.6 \mathrm{mg} / \mathrm{dL}$; and TG, $136.2 \pm 93.0 \mathrm{mg} / \mathrm{dL}$.}

Statins were the most commonly prescribed LMTs, reported in $1,004(97.1 \%)$ patients, mostly as monotherapy $(n=922$, $89.2 \%$ ) (Table 3$)$. Of the patients using statins, $7.8 \%(n=78)$ of

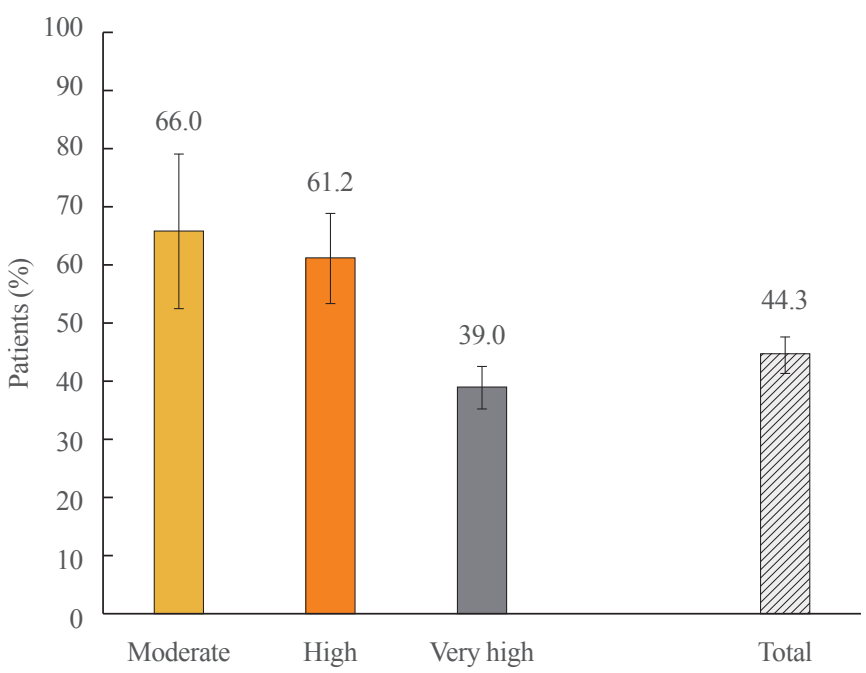

Fig. 2. Target low-density lipoprotein cholesterol achievement according to cardiovascular risk strata. Error bars represent $95 \%$ confidence intervals. overall patients and $9.1 \%(n=66)$ of very high-risk patients were taking high-intensity statins. The maximum permissible dose of high-intensity statins had been prescribed to $7.4 \%(n=74)$ of overall patients and $7.3 \%(n=53)$ of very high-risk patients. The most common $(84.5 \%)$ reason for not prescribing highest permissible dose of statins was cited as physician satisfaction with patient's LDL-C levels from current dosage (Table 3).

\section{LDL-C target achievement}

Overall achievement of target LDL-C was reported in 44.3\% (n/ total number $=431 / 973$ ) of the patients (Fig. 2). Proportions of patients attaining target LDL-C levels in each risk group were $-66.0 \%(n /$ total number $=31 / 47)$ in the moderate-risk group; $61.2 \%(n /$ total number $=109 / 178)$ in the high-risk group; and $39.0 \%(n /$ total number $=291 / 747)$ in the very high-risk group. Of the 129 patients who were statin-intolerant, $39.3 \%(n=55)$ had achieved their LDL-C target; in contrast to $45.2 \%$ ( $n /$ total number $=376 / 832$ ) of the remainder of the patients who were statin-tolerant. On the other hand, patients who had experienced ACS/MI in the 12 months preceding study enrollment had a lower rate of target achievement in comparison to those who had no such experience ( $34.4 \%$ vs. $44.8 \%)$.

Table 3. Patterns in Prescription of Lipid-Modifying Treatments According to Risk Stratification

\begin{tabular}{|c|c|c|c|c|c|c|}
\hline \multirow[b]{2}{*}{ Variable } & \multicolumn{5}{|c|}{ Risk category } & \multirow{2}{*}{$\begin{array}{c}\text { Total } \\
(n=1,034)\end{array}$} \\
\hline & $\begin{array}{c}\text { Low } \\
(n=1)\end{array}$ & $\begin{array}{c}\text { Moderate } \\
(n=47)\end{array}$ & $\begin{array}{c}\text { High } \\
(n=178)\end{array}$ & $\begin{array}{l}\text { Very high } \\
(n=747)\end{array}$ & $\begin{array}{c}\text { Non-assessable }{ }^{\mathrm{a}} \\
\quad(n=61)\end{array}$ & \\
\hline \multicolumn{7}{|l|}{ Lipid-modifying treatment } \\
\hline Statins & $1(100)$ & $47(100)$ & $169(94.9)$ & $729(97.6)$ & $58(95.1)$ & $1,004(97.1)$ \\
\hline Fibrates & 0 & 0 & $10(5.6)$ & $27(3.6)$ & $4(6.6)$ & $41(4.0)$ \\
\hline Omega-3 fatty acids & 0 & $2(4.3)$ & $8(4.5)$ & $29(3.9)$ & $1(1.6)$ & $40(3.9)$ \\
\hline Cholesterol absorption inhibitors & 0 & $6(12.8)$ & $6(3.4)$ & $19(2.5)$ & 0 & $31(3.0)$ \\
\hline Others & 0 & 0 & 0 & $6(0.8)$ & 0 & $6(0.6)$ \\
\hline Patients receiving high-intensity statins ${ }^{\mathrm{b}}$ & 0 & $2(4.3)$ & $9(5.3)$ & $66(9.1)$ & $1(1.7)$ & $78(7.8)$ \\
\hline Patients receiving highest permissible dose of statins & 0 & $2(4.3)$ & $15(8.9)$ & $53(7.3)$ & $4(6.9)$ & $74(7.4)$ \\
\hline \multicolumn{7}{|l|}{ Reason for not prescribing the highest dose of statins } \\
\hline Assessed number of patients & 1 & 45 & 154 & 664 & 54 & 918 \\
\hline Physician satisfaction $^{\mathrm{c}}$ & 0 & $35(77.8)$ & $141(91.6)$ & $550(82.8)$ & $50(92.6)$ & $776(84.5)$ \\
\hline Medically inappropriate ${ }^{d}$ & $1(100)$ & $9(20.0)$ & $9(5.8)$ & $154(23.2)$ & $13(24.1)$ & $186(20.3)$ \\
\hline Statin intolerance ${ }^{\mathrm{e}}$ & 0 & $1(2.2)$ & $4(2.6)$ & $15(2.3)$ & 0 & $20(2.2)$ \\
\hline
\end{tabular}




\section{DISCUSSION}

Periodic assessment of real-world clinical data on the management of CV risk factors such as dyslipidemia is essential to gauge the effectiveness of disease management guidelines. In our study, aimed at ascertaining target LDL-C achievement in Korean patients with dyslipidemia, risk-stratified according to ESC/EAS (2011) guidelines, a substantial proportion of the study patients were already in the very high-risk category. Overall target LDL-C was achieved in less than half of the patients and this proportion was inversely associated with risk categorization. We also discovered that study patients who were statinintolerant or had ACS/MI in the preceding 12 months had poorer target achievement rates in comparison to the other patients.

Despite a large volume of clinical data and established guidelines from numerous medical associations, achieving target LDL-C levels in patients with dyslipidemia has been somewhat less than optimal and inconsistent across periods and regions. In one of the first large-scale, multinational studies conducted in almost 10,000 patients, the lipid treatment assessment project 2 (LTAP2), the target achievement rate ranged between $47.0 \%$ and $84.0 \%$ [28]. Interestingly, this study also enrolled almost 1,000 Korean patients in whom target achievement was reported to be $83.5 \%$, even though $68.0 \%$ of the patients were in the high-risk category according to the National Cholesterol Education Program Adult Treatment Panel III guidelines [29]. The Dyslipidemia International Study (DYSIS) which was conducted in 30 countries and analyzed $\geq 50,000$ patients who were risk-stratified according to the ESC/EAS (2011) guidelines, reported a target achievement rate in between $14.3 \%$ and $49.5 \%$ [30]. In both the LTAP2 and DYSIS investigations, patients in the higher risk strata or with other CV comorbidities had a substantially lower target achievement rate. These findings have also been replicated in the Asian content by the Centralized PanRegional Surveys on the Undertreatment of Hypercholesterolaemia (CEPHEUS) Pan-Asian study, which showed LDL-C target achievement in $49.4 \%$ of overall patients [31].

Attainment of lipid indices such as LDL-C have been clinically validated to depend on various factors such as disease progression, time to diagnosis and commencement and intensification of treatment regimens. Late detection of dyslipidemia, inertia in timely and appropriate interventions, as well as presence of other CV comorbidities might also contribute to suboptimal reduction in LDL-C levels. As high physicians' satisfaction ( $84.5 \%$ in overall) with the current LDL-C levels was revealed to be the prime reason for not prescribing high-intensity or high- est dose of statins regardless of either accordance to guidelines recommendation or achieving risk-stratified LDL-C target levels in this study, their physicians' insufficient of awareness of guidelines might be the major factor of non-adherence to guidelines and, consequently, failure in achieving target LDL-C levels [32-34]. In line with this hypothesis, physicians underestimated the risk levels for $71.6 \%$ of all patients in this study and target achievement of LDL-C levels was only $44.3 \%$. Moreover, the underestimation and target achievement of LDL-C rates were as high as $79.9 \%$ and as low as $39.0 \%$ among very highrisk patients, respectively. Since a prerequisite for evidencebased management of dyslipidemia is appropriate risk stratification, the discordance in risk assessment could have a substantial bearing on the outcomes. For example, a recent study [35] showed that only $42.4 \%$ of the patients who were recommended for statin therapy were on the recommended statin intensity. In the study, untreated $(25.3 \%)$ and undertreated (32.3\%) patients had significantly higher LDL-C levels than the ones on recommended statin intensity. Interestingly, another recent study revealed that Korean cardiologists tend to be more determined in LMTs and achieve higher goal attainment rate than other Asian cardiologists in the CEPHEUS study [36]. Further investigation would be needed to identify factors influencing physician's stratification of CV risk and adherence to guidelines' recommendation for statin intensity especially in Korea.

Given the complex nature of metabolic disease and its relation to CVD, it is practically impossible for a single study to decipher all relevant and multimodal pathways involved. The goal of our study was to answer one key practical question - what is the rate of LDL-C target achievement in Korean patients in realworld settings? Certain aspects of dyslipidemia treatment were beyond the scope of our study; we could not ascertain patient adherence, a factor critical to any chronic therapy. Moreover, no follow-up visits were planned in the study to monitor patients for changes in LDL-C levels. We were also unable to ascertain specific treatments or regimens that were more successful than others in helping patients achieve their LDL-C targets. However, the overall findings of our study not only serve to reiterate the suboptimal attainment of LDL-C reduction in Korean patients presenting $\mathrm{CV}$ risk but also highlights the need to revise current practices in management of dyslipidemia in Korea. Further studies will need to be conducted in order to fine tune the existing guidelines for successfully lowering the $\mathrm{CV}$ risk posed by dyslipidemia in the Korean population. 


\section{CONFLICTS OF INTEREST}

One of the co-authors, Ji-Hyun Kim, is a current employee at Sanofi-Aventis Korea, but no potential conflict of interest was reported by the author.

This study was supported by Sanofi-Aventis Korea. Medical writing and editorial support in the preparation of this publication was provided by Satyendra Shenoy from Describe Scientific Writing \& Communications who was paid for by SanofiAventis Korea and Anahita Gouri and Rohan Mitra from SanofiAventis Korea. The authors individually and collectively are responsible for all content and editorial decisions and received no payment from Sanofi-Aventis Korea directly or indirectly (through a third party) related to the development/presentation of this publication.

\section{AUTHOR CONTRIBUTIONS}

Conception or design: J.S.K., K.M.C., K.W.L., S.C.L., J.R.C., S.J.O., J.H.K., S.H.C. Acquisition, analysis, or interpretation of data: Y.S.Y., S.Y.L., J.S.K., K.M.C., K.W.L., S.C.L., J.R.C., S.J.O., J.H.K., S.H.C. Drafting the work or revising: Y.S.Y., S.H.C. Final approval of the manuscript: Y.S.Y., S.Y.L., J.S.K., K.M.C., K.W.L., S.C.L., J.R.C., S.J.O., J.H.K., S.H.C.

\section{ORCID}

Ye Seul Yang https://orcid.org/0000-0001-9682-6138

Sung Hee Choi https://orcid.org/0000-0003-0740-8116

\section{REFERENCES}

1. Kim MH, Kim MK, Choi BY, Shin YJ. Prevalence of the metabolic syndrome and its association with cardiovascular diseases in Korea. J Korean Med Sci 2004;19:195-201.

2. Jung KH, Lee SH, Kim BJ, Yu KH, Hong KS, Lee BC, et al. Secular trends in ischemic stroke characteristics in a rapidly developed country: results from the Korean Stroke Registry Study (secular trends in Korean stroke). Circ Cardiovasc Qual Outcomes 2012;5:327-34.

3. Shin HY, Lee JY, Song J, Lee S, Lee J, Lim B, et al. Causeof-death statistics in the Republic of Korea, 2014. J Korean Med Assoc 2016;59:221-32.

4. Roh E, Ko SH, Kwon HS, Kim NH, Kim JH, Kim CS, et al. Prevalence and management of dyslipidemia in Korea: Korea National Health and Nutrition Examination Survey dur- ing 1998 to 2010. Diabetes Metab J 2013;37:433-49.

5. Wilson PW, D'Agostino RB, Levy D, Belanger AM, Silbershatz H, Kannel WB. Prediction of coronary heart disease using risk factor categories. Circulation 1998;97:1837-47.

6. Sharrett AR, Ballantyne CM, Coady SA, Heiss G, Sorlie PD, Catellier D, et al. Coronary heart disease prediction from lipoprotein cholesterol levels, triglycerides, lipoprotein(a), apolipoproteins A-I and B, and HDL density subfractions: the Atherosclerosis Risk in Communities (ARIC) Study. Circulation 2001;104:1108-13.

7. Howard BV, Robbins DC, Sievers ML, Lee ET, Rhoades D, Devereux RB, et al. LDL cholesterol as a strong predictor of coronary heart disease in diabetic individuals with insulin resistance and low LDL: the Strong Heart Study. Arterioscler Thromb Vasc Biol 2000;20:830-5.

8. Kim HC. Epidemiology of dyslipidemia in Korea. J Korean Med Assoc 2016;59:352-7.

9. Choi SJ, Park SH, Lee KS, Park HY. The prevalence, awareness and treatment of high low density lipoprotein-cholesterol in Korean adults without coronary heart diseases: the third Korea national health and nutrition examination survey, 2005. Korean Circ J 2012;42:86-94.

10. Stone NJ, Robinson JG, Lichtenstein AH, Bairey Merz CN, Blum CB, Eckel RH, et al. 2013 ACC/AHA guideline on the treatment of blood cholesterol to reduce atherosclerotic cardiovascular risk in adults: a report of the American College of Cardiology/American Heart Association Task Force on Practice Guidelines. J Am Coll Cardiol 2014;63(25 Pt B):2889-934.

11. Catapano AL, Graham I, De Backer G, Wiklund O, Chapman MJ, Drexel H, et al. 2016 ESC/EAS guidelines for the management of dyslipidaemias. Eur Heart J 2016;37:29993058 .

12. Jacobson TA, Ito MK, Maki KC, Orringer CE, Bays HE, Jones $\mathrm{PH}$, et al. National lipid association recommendations for patient-centered management of dyslipidemia: part 1 . full report. J Clin Lipidol 2015;9:129-69.

13. Expert Dyslipidemia Panel of the International Atherosclerosis Society Panel members. An International Atherosclerosis Society position paper: global recommendations for the management of dyslipidemia: full report. J Clin Lipidol 2014;8:29-60.

14. Committee of Clinical Practice Guideline of the Korean Society of Lipid and Atherosclerosis. 2018 Korean Guidelines for the Management of Dyslipidemia 4th ed [Internet]. Seoul: Korean Society of Lipid and Atherosclerosis; 2018 
[cited 2020 Apr 26]. Available from: http://www.lipid.or.kr/ bbs $/$ index $\cdot h t m l$ ? code $=$ care \& category $=\&$ gubu $n=\&$ page $=1$ $\&$ number $=903 \&$ mode $=$ view $\&$ keyfield $=\&$ key $=$.

15. Scandinavian Simvastatin Survival Study Group. Randomised trial of cholesterol lowering in 4444 patients with coronary heart disease: the Scandinavian Simvastatin Survival Study (4S). Lancet 1994;344:1383-9.

16. Sacks FM, Pfeffer MA, Moye LA, Rouleau JL, Rutherford JD, Cole TG, et al. The effect of pravastatin on coronary events after myocardial infarction in patients with average cholesterol levels. Cholesterol and Recurrent Events Trial investigators. N Engl J Med 1996;335:1001-9.

17. Long-Term Intervention with Pravastatin in Ischaemic Disease (LIPID) Study Group. Prevention of cardiovascular events and death with pravastatin in patients with coronary heart disease and a broad range of initial cholesterol levels. N Engl J Med 1998;339:1349-57.

18. Cholesterol Treatment Trialists' (CTT) Collaborators, Mihaylova B, Emberson J, Blackwell L, Keech A, Simes J, et al. The effects of lowering LDL cholesterol with statin therapy in people at low risk of vascular disease: meta-analysis of individual data from 27 randomised trials. Lancet 2012;380: 581-90.

19. Raghow R. Statins redux: a re-assessment of how statins lower plasma cholesterol. World J Diabetes 2017;8:230-4.

20. Hwang JY, Jung CH, Lee WJ, Park CY, Kim SR, Yoon KH, et al. Low density lipoprotein cholesterol target goal attainment rate and physician perceptions about target goal achievement in Korean patients with diabetes. Diabetes Metab J 2011;35:628-36.

21. Park JE, Chiang CE, Munawar M, Pham GK, Sukonthasarn A, Aquino AR, et al. Lipid-lowering treatment in hypercholesterolaemic patients: the CEPHEUS Pan-Asian survey. Eur J Prev Cardiol 2012;19:781-94.

22. Khang AR, Song YS, Kim KM, Moon JH, Lim S, Park KS, et al. Comparison of different statin therapy to change lowdensity lipoprotein cholesterol and high-density lipoprotein cholesterol level in Korean patients with and without diabetes. J Clin Lipidol 2016;10:528-37.

23. Kim HC. Knowledge gap regarding low density lipoproteincholesterol levels in Koreans. Korean Circ J 2012;42:80-2.

24. Danchin N, Almahmeed W, Al-Rasadi K, Azuri J, Berrah A, Cuneo CA, et al. Achievement of low-density lipoprotein cholesterol goals in 18 countries outside Western Europe: the International ChoLesterol management Practice Study (ICLPS). Eur J Prev Cardiol 2018;25:1087-94.
25. Catapano AL, Reiner Z, de Backer G, Graham I, Taskinen MR, Wiklund O, et al. ESC/EAS guidelines for the management of dyslipidaemias: the task force for the management of dyslipidaemias of the European Society of Cardiology (ESC) and the European Atherosclerosis Society (EAS). Atherosclerosis 2011;217:3-46.

26. Conroy RM, Pyorala K, Fitzgerald AP, Sans S, Menotti A, De Backer G, et al. Estimation of ten-year risk of fatal cardiovascular disease in Europe: the SCORE project. Eur Heart J 2003;24:987-1003.

27. WHO Human Genetics Programme. Familial hypercholesterolaemia (FH): report of a second WHO consultation, Geneva, 4 Sep 1998 [Internet]. Geneva: WHO; c2020 [cited 2020 Apr 26]. https://apps.who.int/iris/handle/10665/66346.

28. Waters DD, Brotons C, Chiang CW, Ferrieres J, Foody J, Jukema JW, et al. Lipid treatment assessment project 2: a multinational survey to evaluate the proportion of patients achieving low-density lipoprotein cholesterol goals. Circulation 2009;120:28-34.

29. Expert Panel on Detection, Evaluation, and Treatment of High Blood Cholesterol in Adults. Executive summary of the third report of the National Cholesterol Education Program (NCEP) expert panel on detection, evaluation, and treatment of high blood cholesterol in adults (Adult Treatment Panel III). JAMA 2001;285:2486-97.

30. Gitt AK, Lautsch D, Ferrieres J, Kastelein J, Drexel H, Horack M, et al. Low-density lipoprotein cholesterol in a global cohort of 57,885 statin-treated patients. Atherosclerosis 2016;255:200-9.

31. Chiang CE, Ferrieres J, Gotcheva NN, Raal FJ, Shehab A, Sung J, et al. Suboptimal control of lipid levels: results from 29 countries participating in the centralized pan-regional surveys on the undertreatment of hypercholesterolaemia (CEPHEUS). J Atheroscler Thromb 2016;23:567-87.

32. Reiner Z, Sonicki Z, Tedeschi-Reiner E. Physicians' perception, knowledge and awareness of cardiovascular risk factors and adherence to prevention guidelines: the PERCRODOC survey. Atherosclerosis 2010;213:598-603.

33. Vashitz G, Meyer J, Parmet Y, Henkin Y, Peleg R, Gilutz H. Physician adherence to the dyslipidemia guidelines is as challenging an issue as patient adherence. Fam Pract 2011;28:52431.

34. Ding R, Ye P, Zhao S, Zhao D, Yan X, Dong Y, et al. Effect of physician characteristics and knowledge on the quality of dyslipidemia management and LDL-C target goal achievement in China: subgroup analysis of the Dyslipidemia Inter- 
national Study. J Glob Health 2017;7:020702.

35. Navar AM, Wang TY, Li S, Robinson JG, Goldberg AC, Virani $\mathrm{S}$, et al. Lipid management in contemporary community practice: results from the Provider Assessment of Lipid Management (PALM) Registry. Am Heart J 2017;193:84-92.
36. Sung J, Kim SH, Song HR, Chi MH, Park JE. Lipid-lowering treatment practice patterns in Korea: comparison with the data obtained from the CEPHEUS Pan-Asian study. J Atheroscler Thromb 2014;21:1219-27. 